\title{
Hasan Alî Yücel'in Genç Tıbbiyelilere Seslenişi
}

\author{
Semih Baskan
}

Cumhuriyetimizin kurulduğu yıllarda Ulu Önder Mustafa Kemal Atatürk'ün hedeflerinden biri de Ankara'da bir tıp fakültesinin kurulması olmuştur. Bu konudaki görüşlerini T.B.M.M' nin 1936 y1lındaki 5. dönem 2. yasama yılı açılış konuşmasında "Yükseköğretim için, Ankara Üniversitesi'ni kurmak yolunda Tıp Fakültesi'nin yapımından başlayarak, yeni ve en zor çabaların harcanmasını dilerim". sözleriyle dile getiriyordu (1). M. Kemal Atatürk'ün bu dileği 2. Dünya Savaşı'nın başlaması ve bunun getirdiği ekonomik zorluklar nedeniyle uzun süre ertelenmek zorunda kalıyordu. Savaşın sona ermesiyle birlikte bu proje tekrar gündeme getiriliyordu. Bu konudaki en büyük çabayı harcayanların başında da zamanın Milli Eğitim Bakanı Hasan Alî Yücel geliyordu.

Milli Eğitim Bakanı Hasan Alî Yücel Ankara'da Fen Fakültesi'nin açılışında yaptığı ve 9 Kasım 1943 tarihli Ulus Gazetesi'nde yayımlanan konuşmasında "Ankara Fen Fakültesi, Ankara Tip Fakülte'nin de habercisi ve müjdecisi olacaktır" diyerek bu alandaki hazırlıklara işaret ediyordu(2).

Sonunda Ankara Tip Fakültesi 19 Ekim 1945 tarihinde 2. Cumhurbaşkanı rahmetli İsmet İnönü'nün
Iletişim

Semih Baskan

Ankara Üniversitesi Tıp Fakültesi, Genel Cerrahi Anabilim Dal Akademik Yerleşke K4 Katı

Samanpazarı, Ankara

Tel : : (312) 5082667

E-posta adresi : msbaskan@yahoo.com

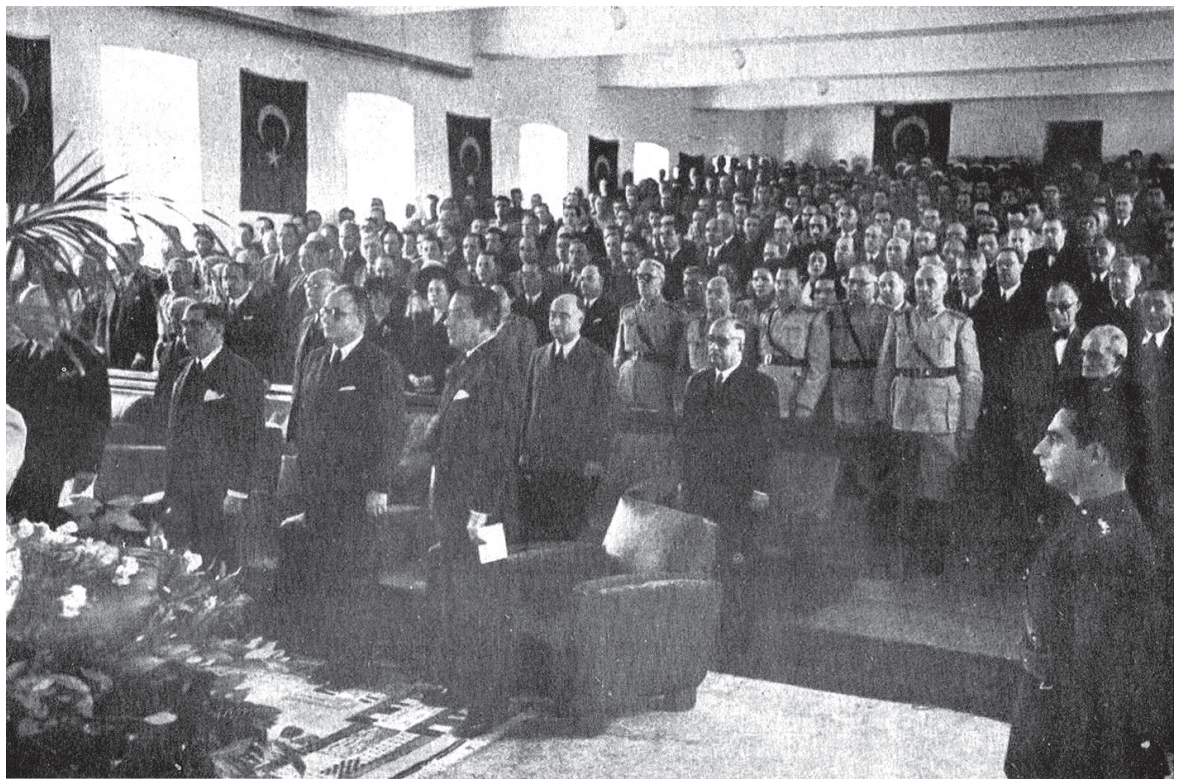

Şekil 1. Ankara Tıp Fakültesi'nin açılış töreni 19.10.1945. 
huzurlarında hizmete açılıyordu. Bu açılış töreninde Milli Eğitim Bakanı Hasan Alî Yücel son derece anlamlı bir konuşma yapıyordu. Bu tarihi konuşma kurulan genç Türkiye Cumhuriyeti'nin bilime, üniversiter anlayışa ve ülkenin sağlık sorunlarına bakışlarını yansıtması açısından son derece önemliydi.

Bu konuda Ankara Tip Fakültesi'nin değerli hocalarından rahmetli Prof. Dr. Fuat Aziz Göksel Ankara Tıp Fakültesi'nin kuruluşunun 50. y1l dönümünde öğrencilere verdiği açılış dersinde bu konudaki görüşlerini şu sözlerle dile getiriyordu. "Bundan 50 yil önce, Fakülte'mizin açılış günü, tören salonunda bulunanlar gerçekten tarihsel bir olaya tanık oldular. Ülkemizin ikinci ve Cumhuriyet Dönemi'nin ilk tıp fakültesinin <doğum travayı> başlamıştı. Başta Cumhurbaşkanı olmak üzere, Devlet'in en yüksek görevlileri, kordiplomatik, seçkin davetliler; öğretim üyeleri ve Fakülte'nin ilk öğrencileri, Türk Basını'nın gözleri ve kulakları orada idi. $O$ gün herkes olayın öneminin farkında ve duygusal bir gerilim içinde idi. Orada yapılan konuşmaların her biri gerçek birer tarihsel belge niteliğini taşırlar. Konuşmalar sona erdi... Etkileyici bir sessizlik, sanki geçmişi gelecekten ayırıyordu. Doğum, an meselesi idi...

Bir canlının dünyaya gelmesi, onun fi'len ortaya çıkması ile, onun ilk çığlığı ile ve nefes alıp vermesi ile gerçekleşir. Bir kurumun doğuşu ise, onun ilk görevine başlaması ile somutlaşır. İşte o an, o kritik an, gelmişti".

Hasan Alî Yücel öğrencilere şöyle sesleniyordu:"

\section{Sayın Arkadaşlar!}

Türk milletinin bütün tarib boyunca insan bayatryla yakından ilgilenmiş bulunduğunu anlatmak için vatanımız üstüne yayılmış canlı belgelere bakmak, bize yeter değerde tanıklar verir. Daba eskilere gidip hafızalarnızı yormamak ibtiyatiyle, durağı belli tup müesseselerinden ve onların ilkinin kurulduğu XII. asrın sonundan başlayabiliriz. Türk Tip Taribi Enstitüsü'nden verilen bilgiye göre sistemli ve üniversiter mabiyette, vatanımız üstünde bulduğumuz ilk tıp ögre-

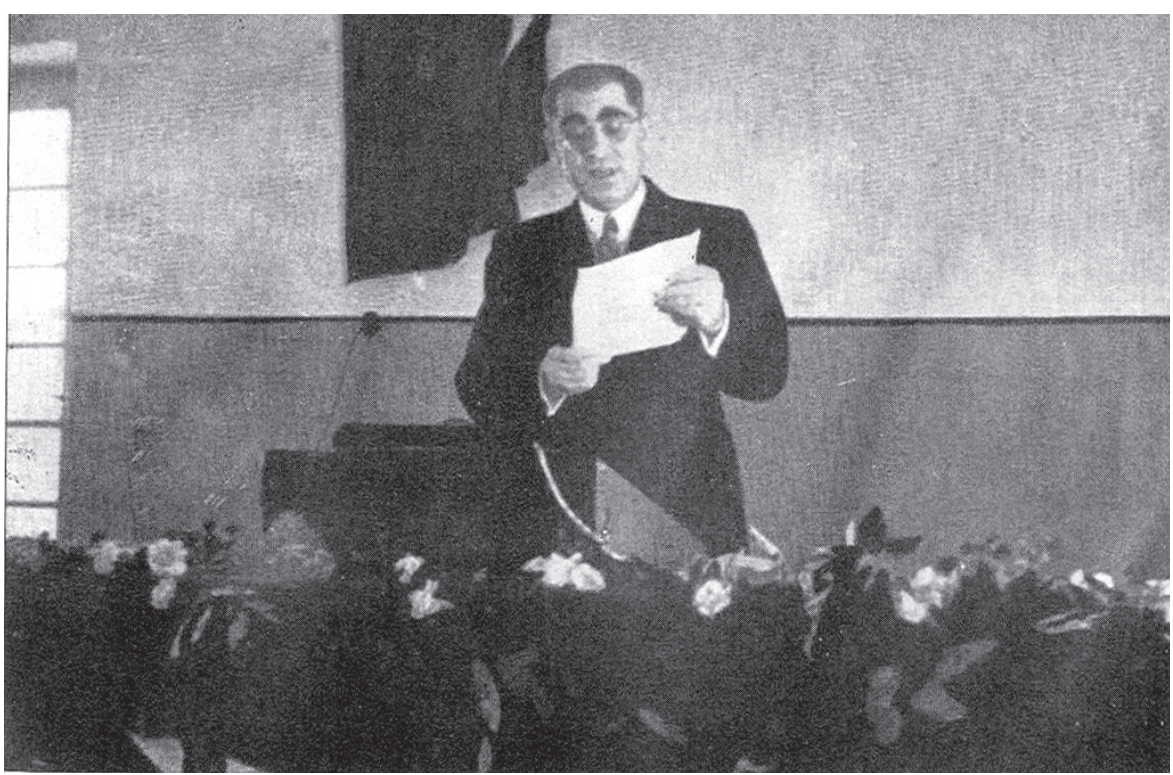

Şekil 2. Milli Eğitim Bakanı Hasan Ali Yücel'in konuşmasını yaparken. tim kurumu, Kayseri'de 1205'te açılan Gıyasettin Keybüsrev I. Tip Medresesi ve onun tatbikat yeri olan Gevber Nesibe Hatun Hastanesi'dir. Bundan 12 sene sonra, Sivas'ta Izzettin Keykâvus I. bastanesiyle yeni bir tup durağ buluyoruz. Aynı asrın ortasına varmadan Divrik'te (Divriği) Turan Melek Hastanesi'nin, Konya Darüşşifasi'nın ve Çankırı Atabek Ferrub Hastanesi'nin açıldığını, bunlar içerisinde hastalara bakıldığı gibi, hastalara bakacakların da yetiştirildiğini görüyoruz. XIII. asr takip eden 200 yulda Anadolu'nun mubtelif yerlerinden bastaneler kuruluyor.

Selçuk devri böylece ve kısaca anlatıldiktan sonra Osmanlilar zamanında ilk düzenli bakım ve öğretim kurumunun Bursa'da ve XIV. asrin son yulında açıldığını söyleyebiliriz. Bu taribin devami yullarinda, Istanbul'da Fatib Darüşsifası, Edirne'de Bayezit II. Darüşsifa ve Medrese-i Etibbası, Üsküdar'da Yavuz Selim Bîmarhânesi, Manisa Hafize Sultan Hastanesi, Istanbul Haseki Hastanesi, Süleymaniye Darüşşifa ve Tip Medresesi, Sultan Abmet Darüşşifası bu yoldaki dikkat, emek, bilgi ile tıp eğitiminin birer anttıdir.

XII. asırdan sonra Osmanlı cemiyetinde başlayan sarsıntı, tıp dünyamizda da kendini bissettiriyor. Söylediklerimize benzer yeni kurumlar açılmadığı gibi eskileri de yavaş yavaş çökmektedir. 1205'te biz Kayseri Darüşsifa'sını kurarken, bilgi diyarı Avrupa'da sayısı ancak üçü bulan buna benzer bilim kurumu vardi. Bizim durduğumuz ve durduğumuz için de gerilediğimiz devirlerde Avrupa'nın Salerno, Bolonya, Paris üniversitelerinin eşleri çoğalmaya, ber dalında pozitif bilgiler gelişmeye başladi. Arka arkaya yenilen Osmanlı ordusunun ıslâbı za- 
ruretleri, top ve tabip ibtiyacin da duyurduğundan, Mabmut II. bekim yetiștirmek üzere bir bilim kurumu açmayı tasarladı. Bizim bekimlerimiz bilgisizlik ve tecrübesizlik yüzünden artık balk nazarında eskiden kazanmiş oldukları güveni kaybetmişler, Dârüttıplarmiz atalar gibi kiymetli bilginler yetistiremez olmuşlardi. Müslüman olmayan Osmanlı'lardan, Avrupa tıp ögretim kurumlarinda yetisip gelenler umumun rağbetini kazanmaya başlamişlardi. Bu zaruret ve bu hava içerisinde 1826'da karar verilip 1827 Mart'inın 14'üncü çarşamba günü "Tiphâne-i Âmire" açıldr. Bundan önce 1805'te Selim III. de Rum tebaamiz tarafindan açılması istenilen Tip Yüksek Okulu'na müsaade ve teşebbüs edenleri, verdiği bir irade ile teşvik etmişti. Bu kurumun hayatı, kesin belli olmamakla beraber, kısa sürdü̈̆̈̈ anlaşılıyor. Bu okulun açılması hakkında verilen iradedeki şu sözler, o devrin tıp durumunu anlatma bakımindan tekrara değer:" Bu konunun düzenlenmesi ber şeyden önce uzman bulunmasina ve önce hastanelerde Anatomi biliminin gösterilmesine bağlıdır. Avrupa'dan Istanbul'a gelen bekimler ber ne kadar tanınmıs eğitim kurumlarinda tip eğitimi görmüsslerse de; değişik alışkanlıklar, iklim özellikleri ve konumlart nedeniyle pek çok konuda hata yaptıklar belli olmuştur. Tip biliminin yerinde ögretilmesinin ttp bilimi uzmanlarinca kesin olarak kabul edildiği ve bu önemli düşüncenin bütün yazarlarca da teslim ve itiraf edildiği kuşku götürmez. Bundan dolayn, ber bölgede hastaneler, hekim eğitim kurumlar ve konunun uzmanlarinin arttirilmasina özen ve dikkat gösterilmesi için benden de çaba beklenmelidir.

Mevcut bekimlerin becerilerinin artması ve bundan sonra yetişecek ögrrencilerin eğitilerek tıp uzmanlarının çoğalması, dallarında uzmanlaşmaları İslâm Ordusu ve genelde bütün halka yararlı ve baytrl olacak, duaları toplayacaktır. Bu boyuttaki tıp eğitim kurumlarında, eğitim işlerinin genişlemesi konusunda Avrupa bastaneleri bekimleriyle iletişim, ameliyat yapma, deneyim artirmak için, gerek hastalıklarda, gerekse anatomi bilgisinde bazı aksaklıkların ortaya çıkması nedeniyle, Istanbul'da mevcut bulunan tıp okulları bu görevi üstlenemeyecektir. Bu konunun, Rum milletine tabsis kulinip, ileri gelenlerden, sadakat ve kabiliyet bakımından ebliyetli ve dirayet$l$, bilim ve eğitime yatkın birisini bakan atayarak ele alınmasinin yürütmeyi kolaylaştıracağı kuşkusuzdur. Bundan dolayı halen Buğdan Voyvodasının kardeşi, değerli Dimitraşko Morozi Beyzâde, bu işe yönetici ve bakan atandiğ zaman kisa sürede top biliminde uzmanlık becerinin arttırılması konusuna dikkat edeceği açık olduğu için"...

Selim III. zamanında açıldiğını söylediğimiz ve taribi hakkinda çok şey bilmediğimiz bu tıp okulunda ögretim dili Rumca; Sultan Mabmut'un açtığ Tiphâne-i Âmire'de ise Fransizca idi. Sultan Mabmut'un, tıbbiyenin açılıs töreninde ögrencilere bitap ederek söylediği nutkun bu parçasını da müsaadenizle okuyacağım:

\section{“Çocuklar,}

Bu büyük ve güzel binayn, Tip Okulu olarak kullanılmak üzere düzenleyerek "Mekteb-i Tibbiye-i Adliye-i Şâhâne" adını verdim. Burada, insanların sağlığına kavuşturulması gibi saygıdeğer bir bizmet verileceğinden bu okulu, diğerlerine tercib ettim. Burada tıp bilimini Fransızca olarak ög- reneceksiniz. Şimdi aklinıza; "Bizim dilimizde ve kitaplarımıda tıp bilimi yok mudur ki yabanci dilde ögrenim görelim?" diye bir soru geldiğini bilirim ve size hak veririm. Size cevap olarak şimdilik var olan güçlükleri, engelleri açıklayarak, bu durumun yakın bir gelecekte düzeltileceğini ümit ve temenni ederim. Gerçekten, tip bilimine dair bizde pek çok kitap bulunmakta olup Avrupalnlar da ilk önce tup bilimini bu kitapla$r$ dillerine çevirip okuyarak öğrendiler. Ancak bu kitaplar Arapça yazılmıştı ve bir süreden beri de İslâm bilginleri tarafindan incelenmesine, öğretilmesine değer verilmediğinden ve giderek bilimin terimlerini iyi bilen bilginlerimiz de azaldığı için söz konusu kitaplar terk edilmis, kullanılmaz duruma gelmişti. Onlarm incelenmesiyle uğraşı tup bilgilerini tamamen Türkçe'ye çevirmek şimdi bem birçok külfete katlanmayı bem de uzun zaman gerektirmektedir. Avrupallar ise bu bilimi, Arapça kitaplardan dillerine çevirdikten sonra yüz yul aşkin bir süreden beri tıptaki gelişmelerle uğraşmişlar, öğretim metotlarinı kolaylaştırmişlar ve sonrada biraz bulus yapıp kendi kitaplarina eklemisler. Simdi onlara göre Arapça tıp kitapları bazı yönlerden eksik gibi görünür. Bu eksikleri, benzerlerinden tamamlamayı göze alsak bile birdenbire Türkçe'ye çevrilmesi mümkün olmayı en az on yul Arapça'nın, sonra da beş-altu ynl tup biliminin ögrrenimiyle uğraşmak gerekir. Biz ise, gerek ordumuz ve gerekse Osmanl ülkesinin ihtiyacı için uzman doktorlar yetiştirip ibtiyaç duyulan bizmetlerde görevlendirip diğer yandan tip bilimini tamamen Türkçe'ye çevirip kitapliğını oluşturmaya çalışmalıyı. Sizlere Fransizca okutmaktan amacım, Fransizca öğretmek değildir. Ancak, tip bilimini öğretip giderek kendi dilimize kazan- 
dirmaktur. Ve ondan sonra Osmanlı ülkesinin ber bir kössesine Türkçe olarak yaymaktır”.

Öğretimin niçin Türkçe yapılmadiğı millî bir duyguyla bu yolda izab edilmekle beraber, o devrin bilgi çevresindeki kanaat şu idi ki şer'î ilimler ancak Arap dilinde, ulum-i dabile dedikleri, bugün bizim pozitif dediğimiz bilgiler ise ancak Frenk dilinde tedvin olunabilirdi. Bu noktaya işaret edişim, dil konusunda bugün ne kadar doğru bir yol tutmuş olduğumuzu ve kültürümüzün dört başl kurulabilmesi için bilim dilinde isabetli başladığımız çalışmalara daba ne kadar emek vermeye mubtaç bulunduğumuzu belirtmek içindedir. Tiphane-i Âmire'nin geçirdiği safhalar ve ondan sonra Istanbul'da tıp öğretimi için açılmıs kurumlarla alınmıs tedbirleri bep biliyoruz. Istanbul Tıp Fakültemiz, Tipbane-i Âmire'nin basir üstünde diz çökerek oturup bocalarını dinleyen, ber türlü öğretim vasitalarindan yoksul (yoksun) talebelerinin uyanık evlâtları elinde nasıl bugünkü bale geldi, bilmem anlatmaya lüzum var mi? Cumburiyet'in tup öğretimi davasında ber imkândan istifade etmek için esirgememis olduğu feyizli dikkati, istikbalin doğru söyleyeceğine emin olduğum vicdanina birakıyorum.

Abdülbamit II. devrinde Maarif Nezareti tarafindan 1884'de yapilan başka tıp okulları açma teşebbüsüne, Sadaretten verilmiş olan cevapta:

"Eğer ki ordu-yu bümayun merkezleri olan yerlerde birer tup mektebi tesisi ve hatta ecnebiler tarafindan ülkenin bazı yerlerinde izin verilen tup mekteplerine olan rağbetin artması mütalâasına dayansa da merkez-i saltanat-ı senniyede bulunan Mekteb-i Tibbiye- $i$ Mülkiye'nin noksanlarmı ta- mamlayarak tamamen istifade olunacak bir bale getirilmeksizin ve fenn-i tup tabsiline elzem olan sair fen bilimlerinin ögrretilmesine kâfi derece-i saniye mektepleri uslab ve tevsi olunmaksızın taşralarca tıp mektepleri tesisi münasip olamayacağından ve muallimler tedarikinde dabi müşkülât çekileceğinden" denilmesi, tarib̂ bir mana taşımaktadir. Bununla beraber 19 yul sonra bu teşebbüs Şam'da gerçekleşmek imkânını bulmuştur. Birçok eksiklerle de olsa 1903 Eylülünde açılma töreni yapilan "Şam Tibbiye Okulu", Suriye'nin bugün de bekim yetiştirmek ibtiyacını karşılayan feyizli bir kurum olarak hayatına devam etmektedir.

XIII. asırdan beri var ettiğimiz tup ögrretim duraklarından birini şu saatte Anadolu'nun ortasinda ve Cumburiyet'in başkentinde açyoruz. Türk milletine sağlik ve esenlik getirecek aydinlari bu kurumda yetiștirecek olan arkadasslarima ve onlara dekan sifatıyla uzun meslek bayatınin olgun tecrübelerini bağışlayan Ord. Profesör Abdülkadir Noyan'a şimdiden başar dileklerimi ve başlamanın büyük şerefi tebriklerimi buzurunuzda sunarm.

Ankara Tıp Fakültesi kolay kurulmamıştır. Öğretim üyeleri, laboratuar ve klinikleri bulmak, öğretici arkadaşlar vazifelerinden ayirarak yeni tıp fakültesine bizmetlerini temin etmek için büyük gayretler sarf ettik. Millî Savunma, Sağlık Bakanları sayın arkadaşlarım Artunkal ile Sadi Konuk'a, Genelkurmay Başkanı Sayın Orbay'a şükranlarm derindir. Teşkil ettikleri bükümetlerde eğitim sorumluluğunu bana vermek güvenini göstermiş olan ve millî eğitim işlerinde başarlarmmz için en müessir yardımlarını bağışlayan iki Başbakanıma duyduğum bağlılık ve saygıy burada belirtirim. An- kara Tıp Fakültesi'nin kurulması teşebbüsüyle Refik Saydam, bu tesebbüsün başarlmasindaki yakın ilgisiyle Şükrü Saraçoğlu adlarını bir şükran konusu olarak bizden sonra geleceklere tevdi ederim.

\section{Arkadaşlarım,}

Atatürk'ün "milli varlığa dayanarak garp medeniyetine tam giriş" anlayışını bize kazandırdığı devrim hamlesini ben de ber Türk aydını gibi şu kutlu günün ışığında bütün yüreğimle tebcil etmeliyim. Bakan olarak Türk eğitimi bizmetinde yedi yulı bitmek üzere bulunan vazifem boyunca, devlet işlerindeki tecrübelerinin, yüksek ve derin görüşünün feyzinden beni nurlandiran, milletimizin ve devletimizin başı Inönü'ye ideal borcumun ve borcumuzun ne değerde olduğunu bu mutlu günde ve tarib önünde anmalıyım.

Sayın Öğretici ve Genç Öğrenci Arkadaslarim,

Mesleğiniz, yorucu, öğrenme zamani uzun, öğrenmeye mecbur ettiği konular çeşitli, hususî hayatınıza kadar tesir edecek güçlükleri size yüklenen bir meslektir. Sizler, insanın varlığında duy duğu acılar kendi varlığınızdakileri unutarak giderme mesuliyetinizdesiniz. Onun için bilginiz kadar ablâkınızın, tecrübeniz kadar karakterinizin kuvvetine mubtaçsinız. Insanlık taribinde zâtını ve adını bulamadığımız ilk bekim, bir bastanin çektiği istırabı dindirme çaresini ilk arayandir. Her bekim bu ilk bekimin duygusuna ermedikçe, ancak bu kurtarıcı mesleğin eciri olmaya mabkûmdur, sabibi değil. Amacı bastayı iyi etmek, hastantn istırabını dindirmek ve böylece bayatı babtiyar olarak uzatmak olan bekimlik, bilgilerin ve sanatlarn akıbeti en büzün vericisi, bunun için de en kutsalıdir. 
Çarelerini bulmak için bütün kuvvetlerini sarf eden bekimin kendisi de hastaları gibi bir gün ölür. Onun içindir ki meslekler arasında, akıbeti amacin yalanlayan bekimlik, mensupların dikkatli ve iradeli şekilde en özgeci ve en bayırl insanlar yapar. Böyle olmayanlar bilgi ve tecrübeleri ne kadar üstün olursa olsun bekim değildirler.

Tıp öğreniminin, günün pozitif bilimleriyle ilgisi, bu bilimin bir kismini laboratuarlara toplamiştır. Fizik, kimya, biyoloji ve bunların türlü dallarinda geniş ve derin ibtisaslar teessüs etmedikçe köklü bir tıp ögrretimi imkânsızdir. Laboratuarlarna kapanı bu konularda sabir ile mevcudu öğrenen ve yenilerini arayan insanlarımız çoğaldiğ nispette Türk bekimliği milletlerarası değerini kazanacaktır. Fakat derbal söyleyeyim ki bekimliğin müspet bilimlere dayanan bu temelleri üstünde bekimi bir artist olmaya zorlayan sezici ve yaratıcı tarafı kliniklerde görülür. Hekim, klinikte sanatkâr, klinikte yapıcı olur.

Bütün bilgiler, bu bakımdan kliniğin ve klinikçinin bizmetindedir. Heykel yontmaya yeni başlayanlar, olgun beykeltıraşı seyrederken, batta yapanın görmeksizin

\section{KAYNAKLAR}

1. TBMM 5. Dönem 2. Yasama Yılı Açılış Konuşmaları. 1 Kasım 1936 Millet Meclisi Tutanak Dergisi. D.5, C.13, Sa:4 eserine bakarken ne büyük şeyler kazanirsa, bir bekim adayı da klinik üstadını görerek, dinleyerek, batta sadece onun çevresine girerek mesleğinin sırrına erer. Öğrencilik, öğretmenlikten daba liyâkat ister. Almasını bilmeyenlere mubtaç olduklarn vermek, çok kereler elde değildir. Öğrenmemenin mesuliyeti öğretenden önce öğrenendedir. Bu duygudaki bir çırak, şüphe etmemelidir ki, bir gün öğreteni geçen bir usta olacaktır. (4)

Içinde bulunduğumuz ber mesele ve ber meslek gibi tup da, nakline çalıştı̆̆ım, insan teki üstünde yapacağı bu emeklerle yetinememektedir. Günün her meselesi ve ber mesleği gibi tup da, sosyal bir zorunluluğun ve sosyal bir ödevin karşısındadır. Cemiyette sağlık diye bir davayı bilinçaltında uyanık tutmadıkça tıp çalışmaları birbirine yakin duvarlarin hapsettiği havalarda boğulmaya mabkûmdur. Onu için bekimlik mesleğine keyfiyetten fedakârlık etmemek şartiyla çok sayıda insan vermeye mecburuz. Hatta diyebilirim ki, keyfiyet yükselmesi de bu sayının artmasına bağlıdir. Bütün Türkiye'de 19 milyona karşı 5636 bekim varken ve bunların çoğu büyük şebirlerde yerleşmiş bulunurken, onlarn arasindan pratisyen bekim, aile ve topluluklar bekimi yanında arayıcı bilgin bekim, elbette şimdikinden çok olamaz. Bizim sağlık davamız yalnız bakıcı bekimle değil, koruyucu bekimlerle de kuvvetlenip çözülecek bir davadir. Önümüzdeki yullar içinde Istanbul ve Ankara Tip Fakültelerinden biç değilse $700-750$ bekim mezun ederek bugünkü toplamı bir katından fazlasılla aşmalıyız. Bize bu kadar da yetmez. Hekim yanında çalışacak yardımcı unsurlar, hastabakucılar ve bemşireler, yüzlerce değil, binlerce yetiştirilmelidir. Bugün bu sağlık kurucu ve koruyucu elemanlarla vücuda getirilecek yaygin bir organ, Türk milletinin ber bakımdan verimini sağlayacaktır. Milletçe ve bükümetçe geçmişte benzeri görülmeyen bir bizla bu davanın peşindeyiz.

19 Ekim 1945, taribimizde babtiyar bir günün ve babtiyar edecek bir günün işareti olsun. Ankara Üniversitesi Tip Fakültesi'ni bep beraber kutlayalım.(4)

Bugün kuruluşunun 63. y1l dönümünü kutlayan Türkiye Cumhuriyeti'nin kurduğu ilk tıp fakültesi olan Ankara Tıp Fakültesi işte değerli devlet adamı Hasan Alî Yücel'in son derece anlamlı bu sözleriyle hizmete giriyordu.

2. Osman Bahadır Cumhuriyet Bilim Teknoloji 1116 Sa:16 8 Ağustos 2008

3. Prof Dr Fuat Aziz Göksel Açılış Dersi, Ankara Üniversitesi Tıp Fakültesi Dekanlık Matbaası
4. Prof Dr Semih Baskan Ankara Tıp Fakültesi'nin Açılış Töreni ve Bu Törende Verilen Söylevler, Ankara, 1995 